\title{
The Information Diagnosis and Analysis of the China National Boxing Championship
}

\author{
Yu Yin ${ }^{1}$, Hu Yihai ${ }^{1}$,Gao Ping ${ }^{1}$,Wu Dacheng ${ }^{1}$, Huang Yu ${ }^{1}$, Liu Ye ${ }^{1}$ \\ ${ }^{1}$ Wuhan Institute of Physical Education, Wuhan , 430079, P.R. China \\ Yuyin310@sina.com
}

\begin{abstract}
Keywords: Information Diagnosis and Analysis ; China National Boxing Championship; Techniques and Tactics; Features
\end{abstract}

\begin{abstract}
Based on using multiple methods which involve literature search, expert interview and data analysis, the article Diagnosed and analyzed the technical and tactical characteristics of the China National Boxing Championship of ten levels which found that there are big difference in the score distribution, frequency of use of boxing, tactical frequency of use, hitting parts of the frequency of use, hitting effective boxing and so, through the comparative analysis, looking for levels of the inherent laws to guide Chinese boxing team on training and competition for better effect, and provide a certain basis on achieving better results in London Olympics.
\end{abstract}

\section{Introduction}

The Boxing Championship of 2011, which includes each level of domestic top ten outstanding players, is significance to our country's boxers to prepare for the London Olympic Game when the game is around the corner. Each level of the championship has nine games. By analyzing the games we can dig the situation of our country all kinds of levels of good players in the game using the technology and tactics. Therefore, coaches can institute corresponding training for his players on the basis of the characteristics, so as to improve the athlete's technique and tactics level.

\section{Object and methods}

Objective. The research object is 20 athletes who participated in the 2011 national men's boxing championship final at all levels .

\section{Methods}

\section{Application of literature}

Browse the China journal net and look up relevant study literature materials especially boxing papers about characteristics analysis of technology and tactics in recent years for preparing for research.

\section{Video analysis}

Obtaining the relevant data through the video of 2011 boxing championship of finals and then analyzing it.

\section{Mathematical statistics}

Using excel software for processing the statistical data of the athletes of the technique and tactics the 20 athletes who participated in the 2011 national men's boxing championship final.

\section{Results and analysis}

Analysis of scores. According to the Figure 1 it can found that the scores is increasing along with the increase of the number of round in the Small levels of the project. The first 3 turns' average score is separately 6.25 points, 7.7 points, 9 points, this suggests that athletes' offense are often more conservative in the early stages of the race, in order to tentatively punches to know the other side's technique features, thus the first round scores are less than the other round. With the competition goes further, athletes have further understanding of opponent's the match against 
method and technical features, they gradually attack are also active up, and the corresponding score has also increased. From the data we can see that the highest stage of score is at the third round. It is because that each round shows the scores of each athlete, so both players exert their effort in the final round.

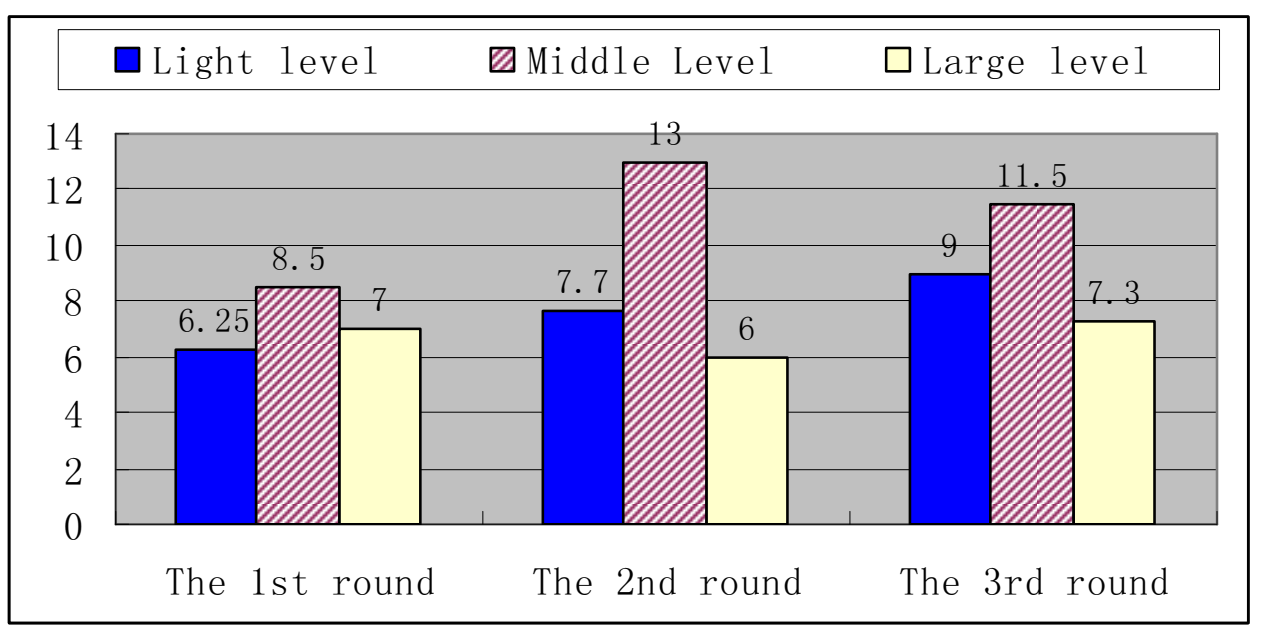

Figure 1. The situation of the average score of each round of each level athletes

The behind athletes want to reverse this situation and the leading player wants to keep the leading edge, thus resulting in higher score. The minimum average score of the middle level of the competition appeared in the first round and the big level's is in the second round. According to the characteristics, we should enhance the athletes scoring consciousness so strengthen their grasp of the ability that make every turn has the ability to keep advantage.

\section{Analysis of the boxing frequency}

Table 1. The analysis of the frequency of boxing

\begin{tabular}{|c|c|c|c|c|c|c|c|c|c|}
\hline Level & Weight & L-str & R-str & L-swi & R-swi & L-hook & R- hook & Double & Combination \\
\hline \multirow{5}{*}{$\begin{array}{l}\text { Light Level } \\
\text { Average } \\
\text { Score }\end{array}$} & $49 \mathrm{~kg}$ & $10: 18$ & $13: 11$ & $30: 45$ & $5: 13$ & $2: 24$ & $2: 20$ & $9: 16$ & $4: 11$ \\
\hline & $52 \mathrm{~kg}$ & $12: 117$ & $10: 40$ & $36: 42$ & $22: 53$ & $6: 10$ & $6: 20$ & $13: 36$ & $8: 29$ \\
\hline & $56 \mathrm{~kg}$ & $39: 15$ & $17: 21$ & $27: 30$ & $21: 17$ & $3: 7$ & $19: 8$ & $14: 8$ & $0: 3$ \\
\hline & $60 \mathrm{~kg}$ & $14: 31$ & $20: 33$ & $21: 19$ & $22: 12$ & $10: 12$ & $23: 20$ & $20: 24$ & $9: 10$ \\
\hline & Average & $18.7: 45.2$ & $15: 26.2$ & $28.5: 34$ & $17.5: 23.7$ & $5.2: 13.2$ & $12.5: 17$ & $14: 21$ & $5.2: 13.2$ \\
\hline \multirow{4}{*}{$\begin{array}{l}\text { Middle } \\
\text { Level } \\
\text { Average } \\
\text { Score }\end{array}$} & $64 \mathrm{~kg}$ & -- & -- & -- & -- & -- & -- & -- & -- \\
\hline & $69 \mathrm{~kg}$ & $57: 27$ & $81: 10$ & $93: 102$ & $63: 102$ & $4: 3$ & $5: 33$ & $36: 41$ & $33: 46$ \\
\hline & $75 \mathrm{~kg}$ & $29: 18$ & $31: 23$ & $26: 39$ & $7: 6$ & $12: 20$ & $9: 8$ & $23: 20$ & $15: 11$ \\
\hline & Average & $43: 22.5$ & $56: 16.5$ & $59.5: 70.5$ & $8: 11.5$ & $7: 20.5$ & $29.5: 30.5$ & $24: 28.5$ & $24: 28.5$ \\
\hline \multirow{4}{*}{$\begin{array}{l}\text { Large Level } \\
\text { Average } \\
\text { Score }\end{array}$} & $81 \mathrm{~kg}$ & $25: 29$ & $29: 32$ & $36: 25$ & $1: 7$ & $10: 11$ & $9: 7$ & $22: 15$ & $15: 13$ \\
\hline & $91 \mathrm{~kg}$ & $26: 16$ & $22: 19$ & $15: 13$ & $10: 8$ & $1: 3$ & $3: 20$ & $13: 4$ & $9: 14$ \\
\hline & $91+\mathrm{kg}$ & $32: 7$ & $21: 45$ & $20: 21$ & $10: 1$ & $11: 1$ & $28: 9$ & $14: 13$ & $12: 4$ \\
\hline & Average & $25.5: 22.5$ & $25.5: 25.5$ & $25.5: 19$ & $5.5: 7.5$ & $5.5: 7$ & $6: 13.5$ & $17.5: 9.5$ & $12: 13.5$ \\
\hline
\end{tabular}

The balance of attack and defense for all against sports are very important, the boxing is not a exception. A good boxer must be "the omnipotence soldier" and at the same time to be "the commando", that means, a good boxing athletes need to have the ability of using various techniques, and also have an outstanding techniques. Table 1 can be founded that the Left swing is most frequently utilized in the light level project, left straight boxing is followed, and combined boxing and the left hook boxing is the lowest. Middle level most frequently utilized the Left swing, right straight boxing is followed, right hook and left hook boxing is the lowest. This is because lift hand boxing faster than right hand, so light and middle level boxers are good at left hand boxing. 
Large level most frequently utilized the right straight boxing, left straight boxing is followed, right hook and left hook boxing is the lowest., this is because the right hand boxing strength bigger than left, and Large level athletes move slower, great strength. It is the situation in all of three levels that the left hook boxing is the lowest frequent utilization. Their ability of attack and defense will become more diverse if utilize more of the fist in the match.

Analysis of the frequency of using various boxing. Comparative anglicizing boxing times of boxing champion and silver medal winner can tell what the players' playing style, custom technology, while the boxing times also has a close relationship with the players level. We can analysis from table 2 that the light level of champion in boxing using frequency averaged only 2 items more than Silver Medal Winner; middle level champions in 4, 5 items more than runner-up; and large level champions had 5 up to, which reflected that as the weight increases, the fierce competition is also increasing along. The majority of the light level champion are flexible style (also called "pirates style" which is giving a fisticuff and escaping instantly) one. It needs to have plenty of strength to do guarantees. The champion and Silver Medal Winner of Middle and large Level in using various boxing getting more closer, the strength getting more weaker as the weight increasing, and the" Standing on the Stake " are using more. Utilizing more flexibility in the changing pace of the game can improve achievement if the players of Middle and large levels have enough physical power as the guarantee.

\section{Analysis and comparative of the number of boxing and effective boxing}

Table 2. The analysis the number of fist and effective punch

\begin{tabular}{llllllllll}
\hline Level & Project & L-str & R-str & L-swi & R-swi & L-hook R- hook Double Combination \\
\hline \multirow{2}{*}{$\begin{array}{l}\text { Light Level } \\
\text { Average }\end{array}$} & Throw a punch & 64 & 41.2 & 62.5 & 41.2 & 18.5 & 29.5 & 35.7 & 18.5 \\
Score & Significant boxing & 2.2 & 5.7 & 6.5 & 3.5 & 0.5 & 3 & 5.5 & 2.2 \\
& Efficient & $3.4 \%$ & $13.8 \%$ & $10.4 \%$ & $8.5 \%$ & $2.7 \%$ & $10.1 \%$ & $15.4 \%$ & $13.5 \%$ \\
& Average efficiency & $9.35 \%$ & & & & & & & \\
Middle & Throw punch & 60.5 & 72.5 & 130 & 89 & 19.5 & 27.5 & 60 & 52.5 \\
Level & Significant boxing & 4.5 & 6.5 & 9 & 2 & 1.5 & 5 & 7.5 & 5.5 \\
Average & Efficient & $7.4 \%$ & $8.9 \%$ & $6.9 \%$ & $2.2 \%$ & $7.6 \%$ & $18.2 \%$ & $12.5 \%$ & $10.4 \%$ \\
Score & Average efficiency & $8.11 \%$ & & & & & & & \\
& Throw a punch & 45 & 56 & 43.3 & 12.3 & 12.3 & 25.3 & 27 & 22.3 \\
Large Level 3 \\
$\begin{array}{l}\text { Average } \\
\text { Score }\end{array}$ & Significant boxing & 0.7 & 7.3 & 4.6 & 2.3 & 3 & 3 & 7 & 4.3 \\
& Efficient & $1.5 \%$ & $13 \%$ & $10.6 \%$ & $18.6 \%$ & $24.3 \%$ & $11.8 \%$ & $25.9 \%$ & $19.2 \%$ \\
\hline
\end{tabular}

Boxer utilizes variety of fist position for different purpose in the match. Fist attack method is to get score directly. Fake action is to confuse the opponent. We can cite the conception of effective punch when evaluate the effect of using varies of fist. Effective punch is able to hit opponent or successfully block attacking opponent boxing. Certainly, as the rule change, the Effective punch scored judgments are also changed .Effective punch is not the very fist which can get score every time. Whether the fist can get score rest with two aspects: the score site and enough strength to make the opponent have a displacement, so, sometimes not directly scoring boxing is effective punch. Comparison analysis the amount of fists and Effective punch can found that boxing effect has some of the practical significance to analysis completion. From table 2 we can found that light level average rate about various Effective punch is $9.35 \%$, the highest is counter about $15.4 \%$, the lowest is left hook about 2.7\%; middle level average rate about various Effective punch is $8.11 \%$, the highest is right hook about $18.2 \%$, the lowest is right straight about $2.2 \%$; large level average rate about various Effective punch is $13.2 \%$, the highest is double hiting about $15.4 \%$, the lowest is right straight about $2.7 \%$. 
Analysis of tactical frequency. Through analysis it can be found players use tactical has a larger difference. From the tactical frequency of use, light level players use it followed the order of press $\rangle$ defend counter $\rangle$ guerrilla $\rangle$ counter $\rangle$ negatively; middle level players use it followed the order of defend counter $\rangle$ press $\rangle$ counter $\rangle$ guerrilla $\rangle$ negative; Large level players use it followed the order of press $\rangle$ defend counter $\rangle$ counter $\rangle$ guerrilla $\rangle$ negative.

On each level players in sort of tactics used there is no large difference, but athletes of different levels of the same tactic used to demonstrate different features, such as defend counter, middle level athlete average used it 31.5 times, and large level athlete average used it 16.3 times. In addition, all level tactical frequency of use has large differences between the champion and Runners-up Winner. Light level champion player use tactics in the defend counter and counter are better than the opponent, and this situation shows that champion athletes have a very strong defense and offensive ability to convert, observe opponent to be attacked at the same time their has awareness of active, before the opponent to attack. Middle Levels Champion player in press, defend counter, counter and negative tactics are better than competitors, description champion player with comprehensive capabilities and advantage on the tactics used. Champion athletes usually use negative tactics show that their physical fitness is deviations.

Table 3. The list of tactical frequency of each level

\begin{tabular}{|c|c|c|c|c|c|c|}
\hline Level & Weight & Press & Defendence & Counter & Guerrilla & Negative \\
\hline \multirow{5}{*}{$\begin{array}{l}\text { Light } \\
\text { Level } \\
\text { Average } \\
\text { Score }\end{array}$} & $49 \mathrm{~kg}$ & $13: 18$ & $15: 11$ & $6: 5$ & $12: 15$ & $0: 0$ \\
\hline & $52 \mathrm{~kg}$ & $13: 19$ & $14: 9$ & $8: 7$ & $11: 15$ & $2: 2$ \\
\hline & $56 \mathrm{~kg}$ & $9: 3$ & $8: 10$ & $9: 6$ & $3: 2$ & $3: 7$ \\
\hline & $60 \mathrm{~kg}$ & $15: 17$ & $10: 8$ & $8: 5$ & $5: 5$ & $0: 1$ \\
\hline & Average & $12.5: 14.2$ & $11.7: 9.5$ & 7.7:5.7 & 7.7:9.1 & $1.2: 2.25$ \\
\hline \multirow{4}{*}{$\begin{array}{l}\text { Middle } \\
\text { Level } \\
\text { Average } \\
\text { Score }\end{array}$} & $64 \mathrm{~kg}$ & -- & -- & -- & -- & -- \\
\hline & $69 \mathrm{~kg}$ & $28: 9$ & $27: 22$ & 11:8 & $0: 1$ & $6: 2$ \\
\hline & $75 \mathrm{~kg}$ & $17: 7$ & $11: 13$ & $5: 3$ & $10: 10$ & $0: 1$ \\
\hline & Average & $22.5: 8$ & $19: 12.5$ & $8: 5.5$ & $5: 5.5$ & $3: 1.5$ \\
\hline \multirow{4}{*}{$\begin{array}{l}\text { Large } \\
\text { Level } \\
\text { Average } \\
\text { Score }\end{array}$} & $81 \mathrm{~kg}$ & $19: 13$ & $8: 8$ & $7: 5$ & $8: 8$ & $1: 1$ \\
\hline & $91 \mathrm{~kg}$ & $13: 19$ & $11: 14$ & $10: 13$ & $5: 7$ & $1: 6$ \\
\hline & $91+\mathrm{kg}$ & $17: 8$ & $3: 5$ & $2: 3$ & $8: 4$ & $1: 3$ \\
\hline & Average & $16.3: 13.3$ & 7.3:9 & $6.3: 7$ & $7: 6.3$ & $1: 3.3$ \\
\hline
\end{tabular}

Analysis of defense. If you can do very well in offensive or defensive counter are likely to bring victory in the competition. From the table 4 can be found, the defend frequency of use about three-level is that the middle level is more than light level and the light level is more than the large level. Champion defend techniques of the light level players on Ducking, sway back and Catch are better than the Silver Medal Winner, suggesting Champion has strong melee defensive skills and has not dependent on a wide range of moves to avoid offensive player attack. Champion of middle level players Sway and Catch techniques are better than the runner-up, reflects that the champion players attacking ability is greater, cause the opponent needs to use more defensive technique. In fact, the runner-up has four defensive technique using frequency higher than the champion. Champion of large level in Ducking and Catch technology are better than Silver Medal Winner, and according to defending both sides the frequency of use can be found Champion attack frequencies higher than the runner-up. Three levels defense using frequency are displayed on characteristics of the Catch first, weaving second 
Analysis of the hitting parts. All levels players hit parts of choice have large difference. Light level athletes struck parts of choice was followed the order of front head $\rangle$ side head $\rangle \mathrm{rib}\rangle \mathrm{abdominal}$ $>$ chest. Middle level athletes struck parts of choice was followed the order of side head $\rangle$ front head \rangle rib $\rangle$ abdominal $\rangle$ chest. large level athletes struck parts of choice was followed the order of side head $\rangle$ front head $\rangle$ rib $\rangle$ abdominal $\rangle$ chest. middle and Large level athletes choose to hit exactly the same parts, select the most times is the side of the head, they are more willing to offense use the speed and intensity of swing; Light levels of athletes the most choice is the head of front, reflects the light level are light-weight, speed fast, the main offensive weapon was struck the fastest of straight punch. Through analysis can found that light level runner-up hitting parts of the frequency of use occupy an absolute advantage but their failed, indicated that the amount of fist of Champion is few but the higher success rate of the effective punch. Middle and large Level champions struck parts of using frequencies higher than runner-up, description champion had an overwhelming advantage and good control ability.

Table 4. The champion and runner-up defensive technique using frequency analysis

\begin{tabular}{|c|c|c|c|c|c|c|c|}
\hline Level & Weight & Weaving & Ducking & Sway & Back & Catch & Flapping \\
\hline \multirow{5}{*}{$\begin{array}{l}\text { Light } \\
\text { Level } \\
\text { Average } \\
\text { Score }\end{array}$} & $49 \mathrm{~kg}$ & $9: 12$ & $2: 6$ & $7: 5$ & $4: 1$ & $27: 3$ & $0: 3$ \\
\hline & $52 \mathrm{~kg}$ & $24: 17$ & $55: 8$ & $5: 6$ & $3: 4$ & $62: 18$ & $8: 7$ \\
\hline & $56 \mathrm{~kg}$ & $7: 12$ & $0: 6$ & $4: 5$ & $3: 3$ & $10: 16$ & $4: 8$ \\
\hline & $60 \mathrm{~kg}$ & $4: 10$ & $4: 7$ & $4: 7$ & $3: 2$ & $11: 7$ & 4: 3 \\
\hline & Average & $11: 12.7$ & $15.2: 6.7$ & $5: 5.7$ & $3.2: 2.5$ & $27.5: 11$ & $4: 5.2$ \\
\hline \multirow{4}{*}{$\begin{array}{l}\text { Middle } \\
\text { Level } \\
\text { Average } \\
\text { Score }\end{array}$} & $64 \mathrm{~kg}$ & -- & -- & -- & -- & -- & -- \\
\hline & $69 \mathrm{~kg}$ & $11: 35$ & $5: 29$ & $2: 1$ & $1: 24$ & $101: 60$ & $0: 1$ \\
\hline & $75 \mathrm{~kg}$ & $18: 9$ & $2: 2$ & $14: 11$ & $2: 1$ & $14: 25$ & $0: 1$ \\
\hline & Average & $14.5: 22$ & $3.5: 15.5$ & $8: 6$ & $1.5: 12.5$ & $57.5: 42.5$ & $0: 1$ \\
\hline \multirow{4}{*}{$\begin{array}{l}\text { Large } \\
\text { Level } \\
\text { Average } \\
\text { Score }\end{array}$} & $81 \mathrm{~kg}$ & $2: 4$ & $1: 3$ & $1: 2$ & $0: 1$ & $16: 6$ & $0: 0$ \\
\hline & $91 \mathrm{~kg}$ & $12: 12$ & $13: 11$ & $8: 8$ & $0: 1$ & $11: 15$ & $4: 5$ \\
\hline & $91+\mathrm{kg}$ & $3: 6$ & $1: 0$ & $1: 0$ & $0: 0$ & $20: 21$ & $0: 0$ \\
\hline & Average & $5.6: 7.3$ & $5: 4.6$ & $3.3: 3.3$ & $0: 0.6$ & 15.6:14 & $1.3: 1.6$ \\
\hline
\end{tabular}

\section{Conclusion}

By the above analysis found that levels of small weight and middle weight players participating in the boxing championship finals, the first round of the competition in relation to other rounds scored is lower, and in the levels of heavy weight there are no major changes;

In the frequency of use of boxing, levels of small weight and middle weight players most commonly used is lead blow, after the Large level players most commonly used is straight punch, Right hook is all levels using the least amount of boxing; small level champion players throw punch frequency less than runner-up contestant, As the level increases, the Championship and runner-up player of the fist step by step closer; Number of levels distribution effective boxing is large level $>$ low level > middle level;

For tactical choices are in the press and counter attack; Defense frequency distribution for the various levels are middle level > low level > large level; On the selection of hit parts, Low level players knock each other face more, middle level players choose the side of the head more . 


\section{Reference}

[1] Honghai Song, Qingmin Fan. 29th Olympic Games boxing match score in skill and tactics analysis [j]. Chinese Sports Science and Technology, 2011.6.

[2] Dexin wang, Qingmin Fan. Best boxers in the world purebdorj. Technical characteristics of saierdanba attack [j]. Journal of Beijing University of Physical Education, 2011.11.

[3] Lisheng Tong. Analysis Xiaoping Zhang win the Olympic Games and national games boxing competition [j]. Journal of Capital Institute of Physical Education, 2011.5. 